\title{
The Mawingu Regional Hospital Maternity Ward
}

The deep-blue walls of the Mawingu Regional Hospital compound usher people arriving on the main road into Sumbawanga Town, a town of some 150,000 residents, located on the Ufipa Plateau, approximately 1,200 kilometers from Tanzania's economic center of Dar es Salaam. The hospital's large plot of land is the same one on which the hospital has sat since at least the 1920s, when the facility numbered a few dilapidated buildings. According to the current staff's collective memory, the oldest buildings still standing on the Mawingu Regional Hospital grounds date to the 1970s. Other wards have risen around this original core, fanning out on the hospital plot. The newest structures include the main operating theaters, the psychiatry unit, and, most importantly for the issues in this book, the maternity ward.

For an understanding of how a hospital can contribute to maintaining high rates of maternal mortality, some background information is necessary. Therefore, I begin by introducing the hospital and the institutional actors who will reappear throughout. These actors make up the characters in this story and include the nurses and doctors, yes, but also documents and paperwork and the physical spaces of care themselves. Situating these actors within the larger context of the Rukwa region and its medical infrastructure helps to draw attention to the importance of each. Additionally, scarcity's influence on the current state and functioning of the health care system in Rukwa becomes clear. This scarcity foregrounds many of the ethical and care negotiations and exchanges that develop throughout the rest of the book.

The first glimpse of scarcity, if you knew how to look, would be visible as you rounded the blue wall's corner and approached the hospital gates. Here you would pass the visitor's waiting area. Relatives always occupied the waiting area: a cluster of concrete benches with an aluminum roof that provided shade during the dry 
season and shelter from the wet in the rainy season. Here relatives from outlying villages waited for their family members to heal or perish, waited to bring family members food or take away soiled clothes for washing, waited to be told to run to a private pharmacy for a critical medication unavailable inside. Clutching brightly colored plastic or woven baskets full of food the hospital did not provide, they waited for the hospital's visiting hours, which happened three times per day for approximately one hour each. Some people, having come from a village and lacking a place to stay in town or any relatives with whom to pass the time when they were not allowed inside the hospital wards, spent the entire day in this waiting area. They waited, whiling away the long hours on the concrete benches worn smooth by many others who had passed the time similarly. This waiting area sometimes acted as a litmus test for the state of the hospital. If I passed relatives crying or if there was commotion in this area, I could expect to hear reports of a death or some other extraordinary event when I sat down in the morning clinical meeting.

Next to the visitors' waiting area, security guards manned the hospital gate and occupied a guardhouse, its spare rooms consisting of a couple of broken chairs and a telephone. The guards were responsible for ensuring that relatives did not roam about the hospital at unsanctioned times. They also inspected all cars for stowaways, ensuring that no patients left the hospital without the proper receipts confirming payment and their discharge cards signed by a doctor. Though most of them knew me, they also subjected my car to search, particularly when I would leave in the middle of the night shift. The guards would ask me to turn on the interior light or open the door so they might look in the back seat and the trunk to ensure that I was not smuggling any patients out of the hospital.

Once I was past the guards, the hospital compound opened up in front (figure 1). A dusty turnaround-cum-parking area in the dry season, it turned into a muddy and cratered expanse during the region's long rainy season. A sign listing the hospital departments greeted visitors to Mawingu's compound. To the far-right side of the compound was a meeting hall, used for the morning clinical meetings, similar to the grand rounds that take place at many hospitals worldwide. In the course of these morning meetings, the hospital staff members gathered to hear reports on the state of the hospital from the previous twenty-four hours, including the number of patients, deaths, admissions, and discharges, as well as a report on the money collected and spent. They also discussed particularly difficult cases in order to decide on subsequent treatment and presented cases in which a patient had died. The medical officer in charge presided over the meeting. These meetings started every weekday morning and included nurses and clinicians from all the hospital departments. The meeting hall was a vital venue, often the only one, for sharing information about the state of the hospital.

This part of the compound, before one entered the hospital proper, also housed offices for both hospital administrators and regional health administrators. In this 


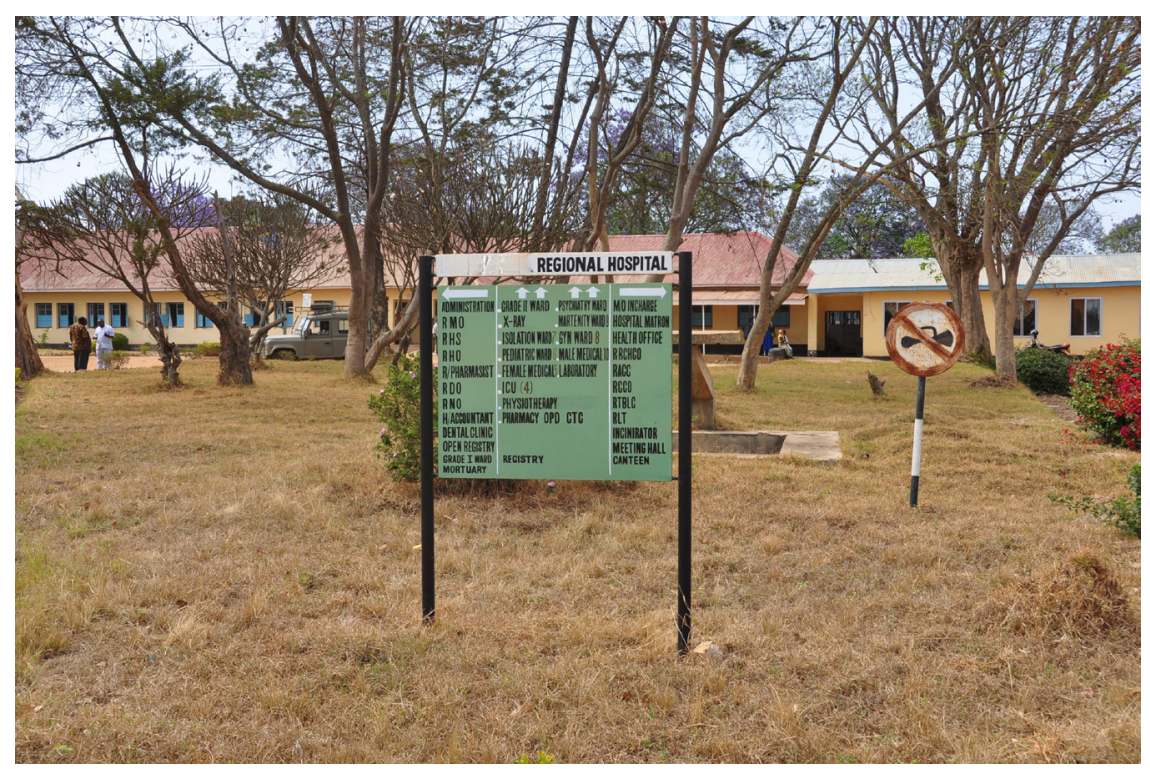

FIGURE 1. View of Mawingu Hospital. Photo by author, 2014.

area, doctors also had offices for consultations and their weekly specialty clinics, such as diabetes and gynecology. Opposite this, the regional administrative block housed the open registry, home to all hospital personnel files; the regional medical officer, the highest-ranking medical official in the region; the regional health secretary; the regional nursing officer; the hospital accountant; and the regional environmental health officer. Next to this building was the Dental Department. Finally, back near the guardhouse, was the Medical Records Department, in a small two-room building with an office and with shelf upon crooked shelf of medical charts and files numbering in the thousands.

The point of entry for nearly all patients, except those going straight to the laboratory or the maternity ward, was the Outpatient Department (OPD). Passing through the main door into the OPD, I had to pass the cash office where often a line of patients or relatives waited to pay the fees required at various steps of the hospital visit or stay. Chipping paint in the uniform colors of government health facilities in Tanzania-pale yellow on top and bright blue from waist level to the cement floors-spotted the walls of the OPD. The OPD itself was a narrow waiting room with several wooden slat benches on which patients and those who accompanied them waited. This area of the hospital could be particularly crowded and hectic but was also supposed to be the first stop for any emergency cases because the hospital lacked an emergency department. I sometimes saw semiconscious people lying on dilapidated gurneys or slumped over in a wheelchair parked near the doctor's door. 
Throughout my time at the hospital, the administration changed their ideas about the ideal method of arrival for pregnant women, convinced at one time that they should all pass through the OPD to be triaged and receive a file, and at another that the best course of action was sending them straight to the maternity ward without any paperwork or notion of their condition. The maternity ward provided the single biggest administrative challenge to hospital management because the number of women coming to give birth routinely eclipsed the number of all other patients two, three, or even four times over.

At the end of the OPD was the pharmacy. A painted iron lattice separated the pharmacy worker from the waiting patients, relatives, or hospital staff members. Papers and medications were passed between these parties through the lattice or via a small opening at the level of a wooden ledge that served as a counter, worn shiny by elbows and hands. A doorway near the pharmacy led out into the hospital compound. From this vantage point, I could look out over the yard, the district medical administrative offices, and then, past a large and flamboyant poinsettia, to the hospital kitchens and, behind that, the laundry and the mortuary.

At the opposite end of the OPD was the doorway to the rest of wards. Mawingu Hospital, like many other hospitals in tropical countries, was built in a style derived from colonial hospital plans, meant to facilitate the flow of air and patients, preventing dangerous miasmas. ${ }^{1}$ The different wards were offshoots of the main walkway.

\section{THE MATERNITY WARD}

The maternity ward was toward the back of the hospital, the furthest point from the entrance. Pregnant women arriving in labor usually proceeded directly to the maternity ward, navigating their uncertainty about both hospital procedures and its layout as they followed the smooth concrete walkway around various corners and the open mouths of the other wards. Upon arriving at the doors to the maternity ward, the pregnant woman generally entered with a female relative or friend who had accompanied her to the facility. Often the relative balanced on her head a plastic basin full of clothes and birth supplies (gloves, a plastic tarp, sometimes an umbilical cord clamp) wrapped up in a colorful kitenge cloth to keep everything contained. They passed through the first set of doors to the ward, then through an anteroom, to enter the ward proper (figure 2).

Several rooms with unique purposes formed the ward. These included the Kangaroo Care Room for premature babies; the antenatal room for women admitted on the ward, perhaps because of health problems or a history of C-sections, but not in active labor; the labor room; the delivery room; the operating theater; the post-Cesarean section room; the postnatal room; and the small room for women readmitted with their babies after birth because of the baby's health condition. In the center of this square was a freestanding, smaller building that contained the 


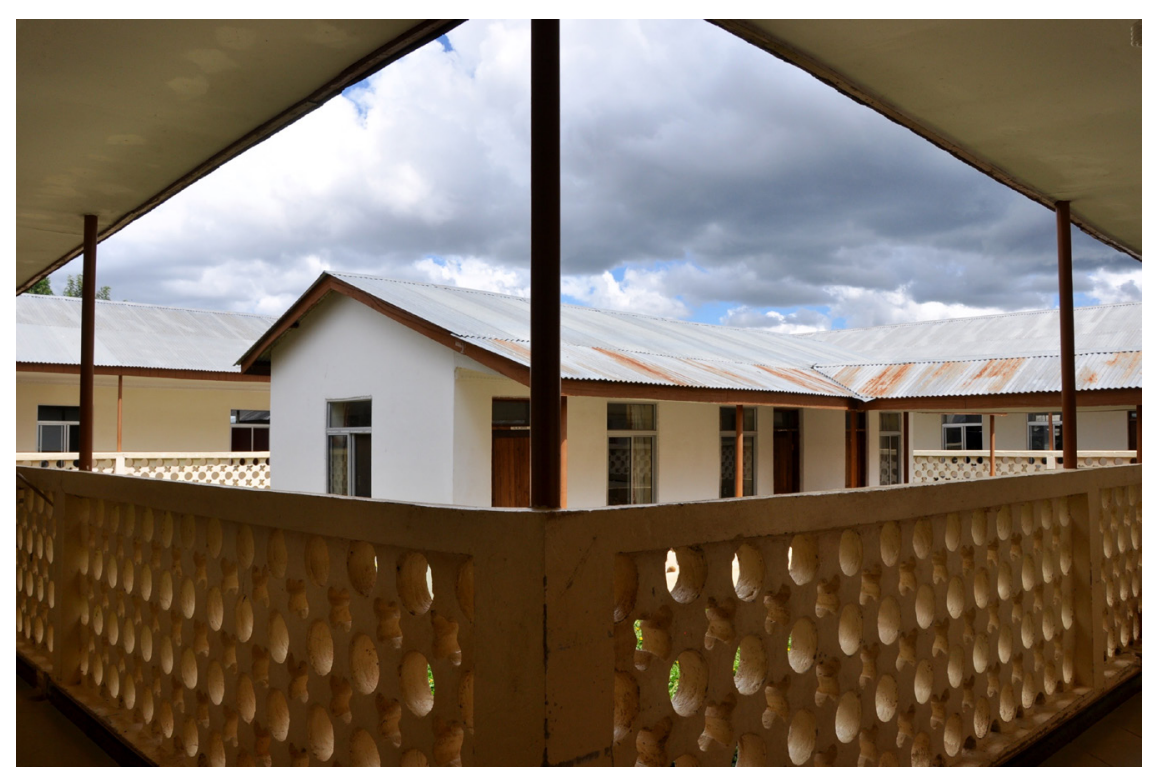

FIGURE 2. Inside the maternity ward. Photo by author, 2014.

offices of the managers of the ward: the ward nurse in charge and the ward medical officer in charge (figure 3 ).

Interspersed throughout these rooms to which women had access was a parallel but prohibited set of rooms that were solely for medical personnel. These spaces included the nurses' changing and break room, staff toilets, a main storeroom for the ward medical supplies, and a storeroom for cleaning supplies, which the male nurses also used as their changing room. The changing room was the most important social location on the ward for the nurses. They used this small room for tea breaks during the workday and as a place to exchange gossip, money, and wedding invitation cards, to conduct side business (such as selling water, snacks, or secondhand clothes), or to discuss private issues (figure 4).

\section{PATIENT FLOWS IN TIME AND SPACE}

Pregnant women, their relatives, and health care workers flowed through these spaces in different ways but along specific tracks. Upon arrival, the patient and her companion reported first to the admission room. This large room was divided into two sections by a chest-height tiled wall. To the left were a number of beds occupied by women in active labor but not ready to give birth, as well as the more critically ill patients or those who needed close monitoring. Women who came to the ward with malaria in pregnancy, severe anemia, infections, preeclampsia, or eclampsia slept in these beds, where the nurses could easily monitor their condition without 


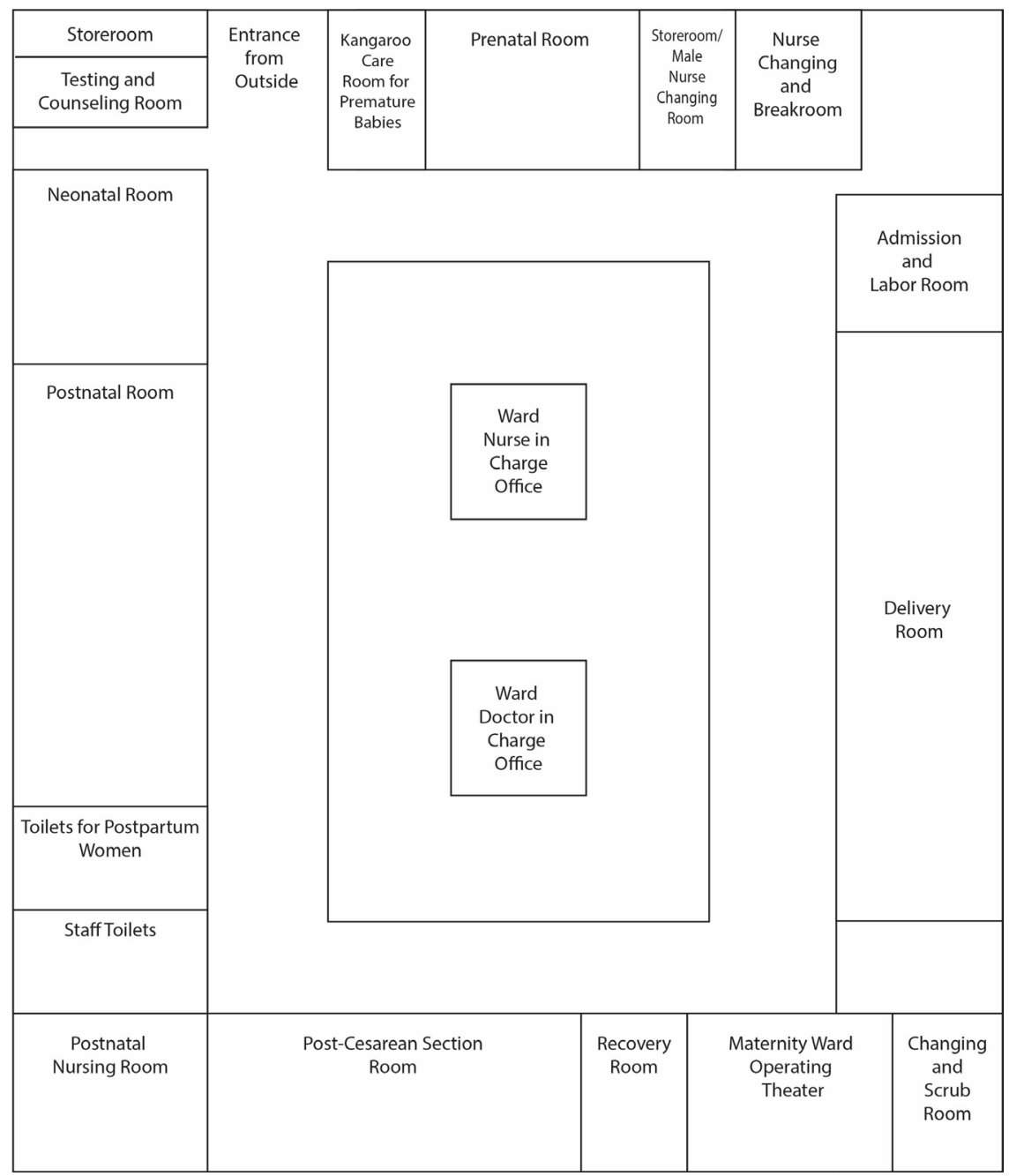

FIGURE 3. Ward floor plan, 2019.

being far from the labor room, which was adjoining. To the right of the wall in the same room was the admission area. This area housed a large desk for filling out paperwork, a wooden bench for arriving women, a waist-high examination bed, a trolley with necessary supplies (gloves, cotton swabs, antiseptic, urine dipsticks), and a handwashing station made out of a plastic bucket with a spigot and a plastic basin on the floor. All women started at this point, in the admission room of the ward. Nurses then funneled them into the appropriate other rooms, sorted and marked out depending on which stage of labor they were in or what other health problems they did or did not have. 


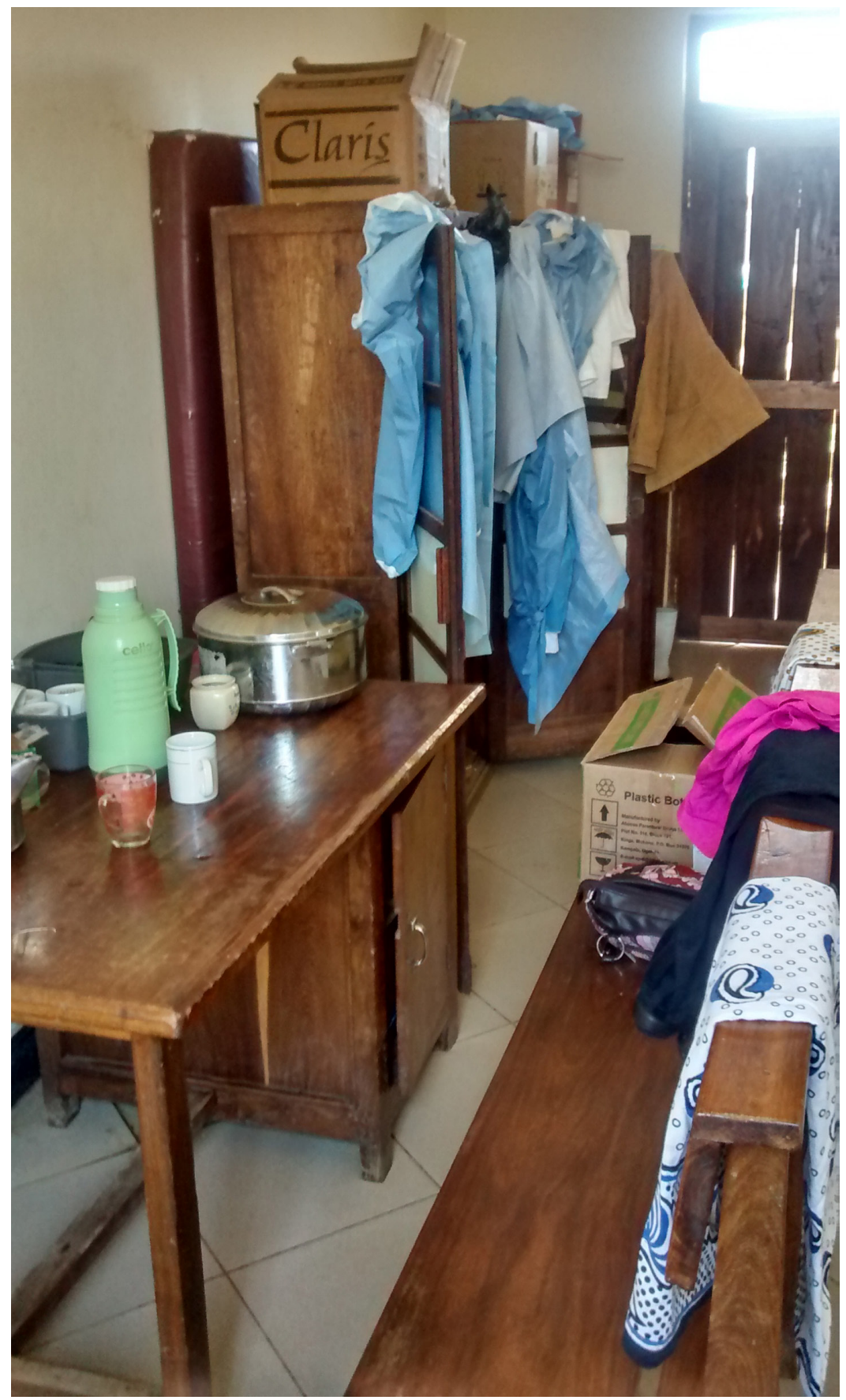

FIGURE 4. View of the break room with boxes of nurses' personal belongings, teacups on the table, disposable protective gowns draped over the cupboard. Photo by author, 2015. 
While those women who lived in the areas surrounding the hospital were familiar with the procedures on the maternity ward and in the hospital more generally because of previous interactions with the system either as patients or as visitors, women who came from outside the district were often confused about how they were supposed to move through these spaces. Nowhere was it written that women in labor could go directly to the maternity ward, and waiting in line in the OPD could cost valuable time. Additionally, when women or their accompanying relatives asked for instructions, they often received gruff responses from harried hospital personnel. Sometimes it was the security guards at the front gate who were most useful in navigating the flows of the hospital. More than once, I witnessed maternity ward nurses harshly telling women they had skipped some portion of the designated procedures and instructing them to return again after they had done it properly-getting the appropriate paperwork, for example, once the hospital had implemented a new accounting and file system.

Ultimately, this confusion about procedures and these difficulties navigating the hospital spaces resulted in much consternation as women in the midst of contractions or a painful pregnancy complication were forced to traverse the hospital, sometimes more than once, in search of the prescribed piece of paper, stamp, or receipt. Delays and bureaucratic procedures that, to women and relatives unfamiliar with the hospital, seemed opaque and unintuitive could produce dissatisfaction with care but also reinforce a woman's sense that she was not in control and would do best to simply be quiet and listen to the instructions of the nurses. This instantiation of a woman's lack of power within the epistemological structure and hierarchy of the hospital served to silence her voice, figuratively and literally, as when she did not tell a nurse she was experiencing a problem she thought was abnormal. In this way, the hospital hierarchy and bureaucratic processes produced in women a sense of uncertainty about when, and how, they could ask for attention from the nurses or doctors. These experiences paved the way for women who remained silent as they began to hemorrhage or felt a change inside their bodies, which later the nurses and doctors might identify as the cause of the woman's death: infection, embolism, shock, life-threatening high blood pressure, cardiomyopathy, or uterine rupture. Women lacked the authoritative knowledge about their own bodies in labor; ${ }^{2}$ this authority was conferred only upon hospital staff members by their affiliation with biomedicine and their training in this system. Women often told me they did not know how to assert their needs, questions, or desires in this hierarchical, power-laden setting in which they were interlopers. The result, in some cases, was stillbirth or the woman's death.

\section{THE NURSES}

The nurses, all of whom had trained in midwifery, did the bulk of the work on the maternity ward. While other groups of hospital staff members had more defined boundaries around their responsibilities, very little was outside the realm 
of nursing work. However, nurses were dependent upon the doctors for the ultimate decisions related to diagnoses and care plans. Within the nursing field in Tanzania were three main categories of nurses, distinguished by their levels of education and training. Enrolled nurses (ENs), in accordance with recent training changes enacted around 2011, went to school for two years to receive a certificate and primarily learned how to conduct uncomplicated deliveries. The older ENs had had around four years of training. Registered nurses (RNs) had either diplomas or degrees. RNs could subsequently continue schooling to become nursing officers (NOs) with university degrees in nursing. Many of the ENs were Fipa and had grown up in Rukwa, often doing their training at one of the nursing schools in the region. The higher levels of nurses often came from other parts of the country and were assigned to the Rukwa region via the government posting mechanisms. Occasionally, some of the Fipa nurses would complain that the hospital administration was favoring nurses from other ethnic groups, particularly those from the neighboring Mbeya region who were Nyakyusa, the same as the hospital's top nursing manager, the patron.

When I first visited Mawingu Regional Hospital in 2012, all of the nurses on the maternity ward were female. In the middle of 2014, the ward received a handful of new nurses, two of whom were male, both ENs. Later, in early 2015, we received another set of new nurses, primarily ENs, three of whom were male. In the end, approximately three-quarters of all the nurses were female. In other parts of Tanzania where I have worked, men have made up a higher proportion of the nursing staff. On other wards of Mawingu, there were more men, including several of the older, more experienced nurses. Indeed, the highest-ranking nurse at the hospital was a man and, as such, had the title of patron, in place of a female matron. His second in charge was a woman and therefore called the assistant matron. During nurse training, the students had to choose to specialize in either midwifery or psychiatry. Historically, I was told, many men had pursued the training in psychiatry; it was only more recently that more men were studying midwifery.

The archival records indicate that during the colonial period nearly all candidates recruited for nurse training programs were female; this was exclusively the case for candidates the colonial administration recruited into training programs as "domiciliary" midwives, nurses, or nurse helpers. One archival file includes many years of documents discussing the suitability of "ayahs for training in domiciliary midwifery," and it is clear these candidates were all women. ${ }^{3}$ This trend is still visible in the profession in Tanzania. At present, the number of male nurses overall, and in midwifery services in particular, is growing, but data from 2008 show that 91 percent of nurse-midwives were women and 86 percent of nurses overall were female. ${ }^{4}$ Clinicians, including medical doctors (MDs) and clinical officers (COs), are overwhelmingly male, with women making up only 21 percent and 28 percent respectively of these groups. ${ }^{5}$ 
Though women made up the majority of the nursing staff, hospital administrators, often the men, not infrequently made highly gendered comments, disparaging female nurses' hair when they thought it was too ostentatious, or insinuating that female nurses were looking for love interests among their patients when they wore makeup or nice shoes. These comments were insidious and worked to further undermine the nurses' access to formal power within the hospital hierarchy, linking them, instead, to more sexualized or less professionally serious stereotypes and tropes of nurses. ${ }^{6}$

In March 2014, near the start of my fieldwork, twenty-two nurses were assigned to the ward, thirteen RNs and nine ENs. By May 2015, the ward overall included about thirty nurses - enrolled nurses, registered nurses, and nursing officers-as well as three medical attendants and three to four physicians at any given time. The nursing patron said that, according to the ideal stated staffing-level recommendations, the hospital should have seventy-two more assistant nursing officers and twenty-nine more nursing officers, of which there were only four at the time, two of whom worked on the maternity ward. Explaining the ongoing shortage of nurses at the hospital, the patron continued: "Even yesterday you heard at the Nursing Day celebration that if you have a deficiency of nurses you cannot maintain standards. Yesterday we were told that by the guidelines of the WHO, one nurse should be serving six patients per day, but according to the research they have done, one nurse here is helping thirty or even forty patients per day. Therefore, you can see how it is difficult to reach those standards."

Nursing shortages arose because the government, that is, the Ministry of Health, did not open up enough positions in any given year or did not allocate 100 percent of the positions that district or regional administrators requested. Sometimes nurses waited a year or more before the government officially hired them. During this time, they often worked for free in a local hospital to gain experience. To try to produce more nurses more quickly, the government shortened the training time for ENs. This policy change succeeded in turning out more nurses to fill vacancies, but these new school graduates often arrived at work with little practical knowledge, unable to properly perform many procedures. This meant the older, more experienced nurses had to spend time with these new nurses to ensure that their skills were adequate before they could trust them alone during a complicated birth or an emergency situation. The hospital patron once explained to me that he made a concerted effort to assign the more highly trained and experienced nurses to the maternity ward because he recognized how demanding and complicated that work could be. He went on to say, "I have taken more than twenty assistant nursing officers [RNs] to the maternity ward because I know there is a big need. But if we had enough of the assistant nursing officers, I would expect to reduce the number of ENs on maternity [even further], they should be few there." During my time at Mawingu, there were brand-new graduates, along with nurses who were close to retirement and nurses with all manner of experience in between. 
As nurses continue working in the government system, they are supposed to be promoted on a regular basis, every three years, so long as their performance is adequate. Many nurses spoke of these promotions as a right and, at Mawingu, as something that had long been denied to them because of budget constraints and poor administration. These promotions, perhaps most importantly, came with much-needed pay raises. Nurses generally belong to the Tanzania National Nursing Association (TANNA), the Tanzania Midwives Association (TAMA), and the national association for government medical workers. While the hospital employees never told me about a nursing strike in Tanzania, the doctors in the country have gone on strike to demand higher wages and better working conditions. Universally, the nurses I interviewed emphatically told me that their salaries were never enough for their daily family needs. Many of them pursued other forms of income generation, ranging from small-scale trading and selling of homemade snacks, to farming, to acting as middle-people for agricultural goods, to engaging in animal husbandry, to running clothing or home goods shops or, popularly, pharmacies.

The nurses on the maternity ward expressed their continuing feelings of being overburdened even though the hospital administrators told me they had been making a concerted effort for more than a year to increase the staffing levels on the ward. Despite these efforts, the nurses' workloads continued to increase in response to additional documentation demands produced by the hospital itself, as well as outside agencies and the Ministry of Health. This work all occurred in the context of growing demand for the hospital's maternity services.

The number of births per month on the maternity ward, 450 to 600, amounted to the busiest months' seeing around twenty births per twenty-four-hour period, on average. However, maternity care is not an area ruled by averages; some days an entire morning shift of eight hours could pass with only two births. Other days, the same eight-hour period could be nonstop deliveries, including multiple Cesarean sections, entirely overwhelming the staff members on duty and quickly exhausting supplies and equipment. Work on the maternity ward, like nursing care throughout the hospital, was arranged into three shifts-morning, afternoon/evening, and night. The morning shift was eight hours long, the afternoon/evening shift approximately four, and the night shift approximately eleven to twelve hours long.

By the time I left Mawingu in the beginning of June 2015, the morning shift generally had about six assigned nurses, including the ward nurse in charge; the afternoon shift usually had about three nurses, as did the night shift-two on labor and delivery and one assigned to the postnatal portion of the ward. The ward could quickly become understaffed if even one nurse left to run an errand, attend a meeting, or return home to tend a sick child or a funeral unexpectedly. There were around forty beds on the ward, at least half of which almost always were occupied by at least two women. Therefore, a conservative estimate might be that between forty and sixty women, plus the babies of all those who had already 
given birth, were on the ward each day, overseen and cared for by just six nurses, at a maximum, easily exceeding the six-patients-to-one-nurse ratio the patron cited.

On the morning shift there were also usually two medical attendants and two to three cleaners who helped fetch supplies, prepare delivery packs, maintain cleanliness, and generally run errands for the ward, including opening patient files in the Medical Records Department and taking samples to the lab. If these people were not present, the nurses did all of these tasks in addition to the nursing care. Despite efforts to task-shift (i.e., to shift certain duties from higher- to lower-level workers) and enable medical attendants, for example, to complete key tasks such as preparing equipment for delivery kits, Nurse Peninah told me,

Another thing, so much work has to do with the nurse. Therefore, those responsibilities of sharing work, to say that the doctor does these things, the lab person these, these someone from wherever, there isn't any! I mean, any of that work, the nurse does it! . . Everything. So you find that people in a lot of sectors, like the lab, a person is just sitting there, he is waiting for the nurse to do it. A person that is in the pharmacy is just sitting there, she thinks the nurse should do it. ... You see? That is where the difficulty of the work comes in; there is none of that sharing of work responsibilities.

Later in the same conversation, Peninah told me that even though she was one of the most highly qualified nurses on the ward, as determined by formal education, she did not feel that any task was beneath her because, ultimately, it all had to be done, and if she could do it, then she would. This resulted in the endless nature of a nurse's work.

\section{THE CLINICIANS}

I trotted along behind Dr. Charles, trying to keep up, as he rushed into the ward, coming from the obstetrics and gynecology clinic that he ran twice per week in the mornings. As he explained to me, he was delayed in reaching the ward for morning rounds because "you know, everyone comes to the gynecology clinic and they don't want to wait. And because none of the other doctors are around I'm stuck doing it all myself. You see? I'm so late coming here." He grumbled as a side note, "You see? I haven't even gone to the canteen yet for my chai," referring to the small hospital-run cafeteria that offered standard Tanzanian morning "bites" of chapati, doughnut-like maandazi, and the requisite black and milk teas. He continued, "I haven't eaten yet since last night, how am I supposed to continue on? Hopefully there won't be a surgery."

Dr. Charles exchanged joking pleasantries with the nurses on duty as he called out for the trolley for rounds and started reaching for the nearest woman's file, tucked on top of her light-blue mosquito net, which was draped over the rusting, fly-poop-encrusted metal frame suspended from the ceiling. The women, who were in good spirits, or had been on the ward for several days, called out to 
Dr. Charles. Mama Angel teased, "Oh doctor! You are late this morning. What food have you saved for me? Ugali?" Despite having not yet eaten anything, Dr. Charles responded to the standard joke with "This morning, chapati, Mama Angel! I'll bring you some later!" Other women lay on their sides or sat quietly in their beds, withdrawn into themselves out of pain, shyness, or unfamiliarity. With that joke, we were off and running for the rounds, which would cover all the women admitted to the ward. Our little party gained and lost members as we circulated with Dr. Charles; nurses entered his orbit to ask for a signature or clarify orders, and students in the clinical officer training program from the nearby school clustered around to hear Dr. Charles explain a unique case and then peeled away to find someone whose blood pressure they could take or whose file they could study. Through all this, Dr. Charles moved steadily from patient to patient, double-checking with the rounding nurse which medications were in stock or asking to verify that the woman had received the prescribed treatment when the file lacked documentation.

The clinicians, including medical doctors (or medical officers), assistant medical officers (AMOs), and clinical officers, were responsible for conducting patient rounds each day, ideally before noon, to assess each woman's condition, monitor any changes, and prescribe next steps for her care. AMOs have a four-year advanced diploma, and clinical officers have a two-year diploma. The AMOs and clinical officers tended to have more circuitous training routes, often working their way up from lower positions such as medical attendants, nurses, or laboratory staff. Medical officers, on the other hand, frequently described relatively linear educational ascents: they often came from elite private or boarding schools in the country and worked their way through the five years of medical school at the bachelor's level. The clinicians assigned to the maternity ward were nearly all medical officers (MOs/MDs) and all men during my time. The hospital and regional medical administrators, like their nursing administration counterparts, recognized the complex nature of maternity care, and just as nursing administrators wanted to place their most skilled nurses on this ward, so medical administrators sought to direct their most skilled physicians there. Though he was less present, there was one AMO, Dr. Benard, who had long worked on the maternity ward and continued to take on-call shifts. He frequently performed C-sections, like many AMOs throughout the country who had been trained to do so as part of task-shifting initiatives to alleviate the burden on MOs. AMOs and clinical officers were more common in other areas of the hospital, particularly the OPD, where they were primarily responsible for triage and treating common ailments. However, it was also these clinicians with less training who were responsible for receiving many pregnant women in crisis, especially at night.

On the maternity ward, I concentrate primarily on medical officers because they were the most common and most present. Henceforth, I simply refer to them as the doctors. Starting near the end of 2014, physicians rotated through the 
maternity ward much more frequently than had been common in the past, when the same three doctors had worked on the ward for about three years. There were still times throughout my stay when the ward might only have one doctor present, the others being away on annual leave, out sick, or traveling for other job responsibilities. On the day of Paulina's death, I wrote in my notes,

Dr. Deo spent most of the last week entirely alone on the maternity ward. There are usually supposed to be at least four doctors on the ward, but two were traveling, and one, well, I don't know where Dr. Benard was, but I haven't seen him for almost two weeks. So, Deo alone all this past week. Having only one doctor seems to be common so far. Dr. Charles recently was on call essentially $24 / 7$, alone for almost three weeks, and last month he once told me, "If you're the only one here, you're fucked. Either you die or they die," meaning the patients on the ward. In these cases, the doctors basically never had time off.

I came to find Dr. Charles's crassly ironic remark all too true as I watched the doctors and nurses struggle to provide care for their patients while doing so often meant sacrificing their own needs or well-being, including sleep or time to attend to household tasks.

The doctor would conduct rounds with a nurse who recorded a summary of the prescribed care, equipped him with gauze, gloves, plaster (medical tape), and antiseptic as needed, and drew his attention to the most urgent cases. The doctors also personally changed the bandages of women who had had C-sections or other operations, which the medical officer in charge credited as the reason for significant improvements in the hospital's rates of postoperative sepsis and infection. Further, the doctors were responsible for writing all the clinical notes for the women's files, and they saw patients in the weekly obstetrics and gynecology clinic. They were also responsible for the gynecology ward, conducting all gynecological surgeries, as well as C-sections. They rotated on-call duties for any emergencies that occurred after the 3:30 p.m. end of the working day, though they often stayed past that time to finish surgeries, paperwork, or other duties. When multiple doctors were present, they divided the duties on the maternity and gynecology wards to ensure that they could see patients in a timely manner and complete all their duties before the end of the day. Additionally, the doctors participated in meetings, trainings, and provided advice or saw patients whom they knew, perhaps through family or other personal connections.

None of the doctors were originally from Rukwa; most had been posted there by the Ministry of Health or had been recruited through the Benjamin Mkapa Foundation. Dr. Deo had finished school in 2012 and, after completing his internship in Tanga, on the eastern coast of Tanzania, had been working in Rukwa since late 2013. I once asked him how he had felt when he found out he had been assigned to start work in Rukwa and whether he had ever been there before learning of his posting. He told me, "No! I was just told, 'Tomorrow, come see your-you know, 
where you have been taken to. So, the next day I went, I was told that I have been planned at RAS Rukwa. I was shocked, (in English) Where is Rukwa? I came to know that this here is Rukwa, I felt so bad." He went on to tell me that he had been encouraged to come because Dr. Fakhiri, whom he knew from their internship time in Tanga, had also been posted to Mawingu, in another department. Dr. Fakhiri went without hesitation and subsequently encouraged Dr. Deo to also go.

"Why were you worried about your assignment?" I prompted.

"Ah, there were these stories that there are witches here, but when I came, I saw it was different. But the thing that was making me afraid was that about witches." I nodded in encouragement, and he continued, "I mean, that's to say, when we had arrived at Tunduma [the largest town closest to Sumbawanga where the paved road used to end] I wasn't seeing any electrical wires. It was necessary for me to ask people, 'Friends, there, there isn't any electricity?' They told me it was there, so I came, life started, until today. Although, when I was coming here, I had planned the fare to return entirely, but I came to delay that." Other physicians, particularly specialists, who had been assigned to the region never even made that first trip to see it for themselves.

When I started working in Rukwa in 2012, the Sumbawanga Urban District Council reported that only 51 percent of health care positions were filled and that the problem was worse in the rural areas outside of town. ${ }^{7}$ Nurses and doctors related many stories in which health care workers assigned to the region reported for work and then disappeared again. Many others, including several of the nurses with whom I worked on the maternity ward, were actively pursuing transfer requests to move outside Rukwa. This trend is not new. This region presented persistent problems for colonial administrators, who routinely struggled to meet the needs of the people living in the area while also supporting health care personnel. This struggle was exacerbated by limited connections to other regions of the country and lack of access to reliable postal and telecommunications infrastructure due to the isolation caused by natural geographic barriers and by a lack of significant earlier, German colonial efforts to infiltrate the region. The region has only recently started to change, and colonial challenges related to retaining health care workers and geographic isolation would sound familiar to anyone who has lived in Rukwa in the last twenty years.

\section{THE DOCUMENTS}

As much as the doctors, nurses, and pregnant women patients appear to be the key players in this story, there is one character still to introduce, the documents. The corpus of text produced each day, week, and month on the maternity ward was overwhelming, and the nurses were responsible for the vast majority of it. Though 
the doctors, like Dr. Charles, wrote notes in patients' files and documented their clinical progress, it was the nurses who were primarily responsible for maintaining the documentation for each woman, baby, procedure, supply, shift handover report, death, or birth registration. They also documented all HIV testing, the patients on the ward who were receiving hospital meals, and the number of patients-adult and infant - on the ward at the end of every shift. Some of the record books were in Swahili, but the staff members wrote all official hospital reports, including the daily morning, afternoon, and night shift reports, in English, the country's second official language.

As time passed at Mawingu, the stack of notebooks on the nursing desk in the labor room steadily grew. This stack was paired with a smaller one in the postnatal section of the ward, and all of these eventually met up with the books and files in the nurse in charge's office in the form of monthly reports that the ward submitted to the hospital and then to the regional and national levels. Starting in September 2014, the nurses also began documenting every piece of equipment and every supply they used while caring for each woman, scrupulously listing each item and its number count in the woman's paperwork and repeating this again in a notebook newly acquired for the purpose. The hospital administration had added this documentary requirement in an effort to ensure efficiency and responsible use of supplies. Newly available numbers from a computerized accounting system had led some administrators to express concern that the maternity ward was misusing supplies because of what appeared to be vast consumption, far different from that of other wards. In fact, the ward simply had many more patients.

In the course of daily life on the ward it was impossible not to continually encounter these various documents, the paper residue of lives and treatment, rumor and clinical decisions, state and global policy. Sometimes, as with the notebooks, the paperwork remained well-behaved and stationary, while at other times the forms were unruly and tended toward wandering.

"I can't find it!" Nurse Neema threw her hands up in exasperation as she walked into the delivery room where I was sitting at the well-worn desk, fiddling with my phone. It was a slow morning, and one woman labored quietly nearby, slowly pacing with a green plastic cup of tea balanced in the palm of her hand. I pulled my eyes away from the phone. "What are you looking for? Can I help?"

"This patient says she was here last week and that we admitted her for three days and sent her home because she wasn't in true labor. Now she has returned and I can't find her records anywhere!"

"Let me see if I can find them," I told her.

"Yes, you are always pulling out those papers, saying, 'Takataka, takataka!' Go look for this file in those takataka." I laughed as the tension in her shoulders eased just a touch and Neema turned to go back through the swinging doors to the admission room, on to another task. 
The nurses knew that I would routinely help with ward cleaning by going through the stacks of papers in the delivery and admission rooms, good-naturedly muttering about the trash, takataka, that everyone stuffed into the cupboards built into the desks. I gingerly pulled open the crooked door by its worn handle. The cupboard threatened to vomit its contents into my lap as I crouched before it and reached in up to my shoulder, sweeping out rumpled papers of various sorts. Feeling like a fisherwoman bringing in my haul, I swept up partographs and halffilled lab request forms into the basket shaped by my arms as small pages from the physician's prescription pad fluttered to the floor, along with colorful pink and yellow chits from the cash collection system no longer in use. With their greater density, the shiny cardstock trifold antenatal cards plunked to the floor near my feet. I gathered the fallen bits and pieces into a pile that sprawled higgledy-piggledy across my outstretched forearms, and I moved it all to the top of the desk for closer examination. Women's forgotten tetanus vaccine record cards sat together with referral letters laced with entreaties for help from the regional hospital for this or that difficult case - a ruptured uterus here, a case of eclampsia there-that a nurse had hastily thrown into the drawer sometime between receiving the woman and intervening in her obstetric emergency. I peeled apart lab request forms, several of which had never made it to the lab, others with results written in the lab's distinctive red pen at the bottom of the page. Partographs, used to record a woman's progress in labor, had folded up on themselves, concealing the women's names and obstetric histories on the front page. After sorting the papers in the first desk's cupboard, I moved onto the next and repeated the process. After some time, I found the papers Neema wanted; stapled to the partograph of another woman with a similar name, the pages had sunk to the bottom of a pile and drifted into the back of the cabinet.

Documents and documentation requirements structured interactions and decision-making in ways both obvious and subtle. Their presence permeated the ward. Some of these documents were for ward or hospital purposes only, while others had afterlives at the regional and national levels. Here, they either went on to reinforce the region's reputation as a peripheral backwater or served to demonstrate and uphold the region's performance of improvement and compliance with the proliferating guidelines and protocols handed down from the Ministry of Health. At higher levels within the hospital, the nurses' documentation demonstrated their (in)appropriate handling of situations both normal and exceptional. Care that counted was counted care. That is, the documented care constituted the official version of reality. What was on the piece of paper might not reflect the actual sequence of events as they occurred, but the nurses and doctors could manipulate these forms so they included the accepted form of reality that protected them from repercussions or allegations of bad care-either intended, accidental, or otherwise-and, conversely, demonstrated how they were improving outcomes on the ward. 


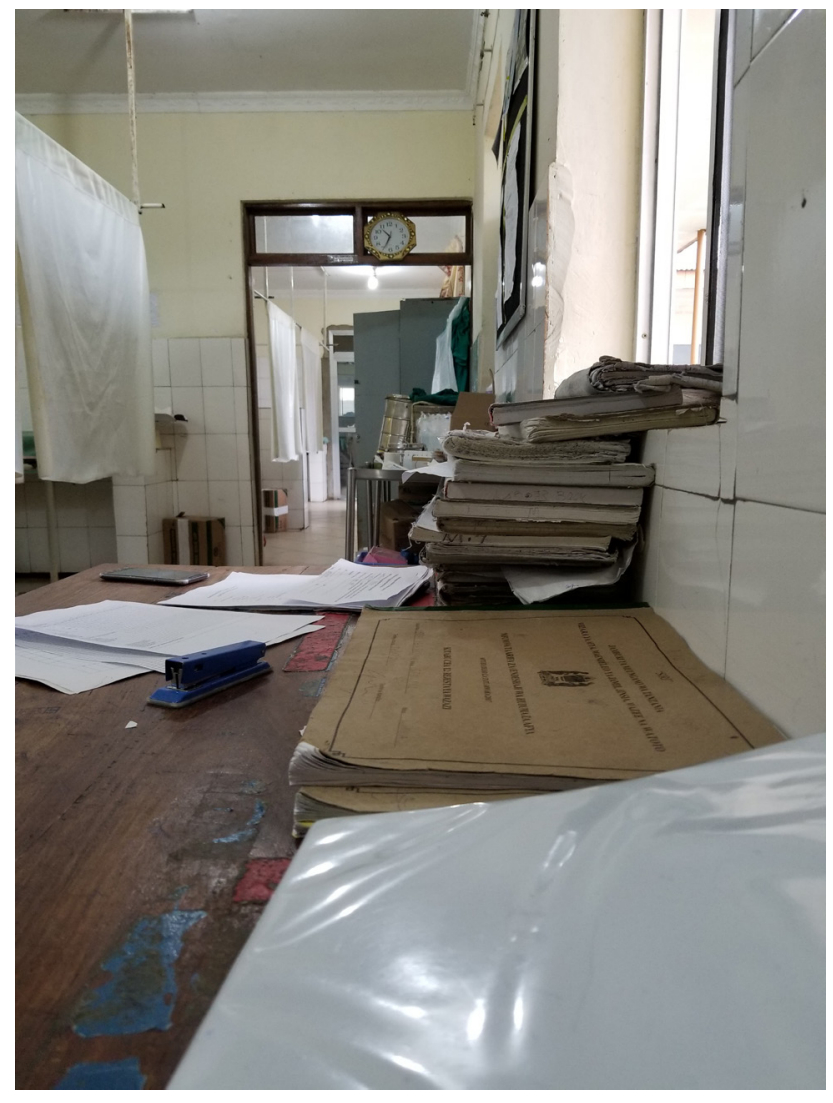

FIGURE 5. A tower of notebooks on the nursing desk in the labor room. Photo by author, 2018.

Every new protocol, guideline, or hospital system generated another notebook or record book (figure 5); these books continued to multiply to accomplish the objectives of outside biobureaucratic institutions and the proliferation of their efforts to track, monitor, supervise, train, and constrain the health care providers working both in urban centers and at the periphery, as well as the bureaucratic efforts of the hospital itself. In addition to accounting and supplies books, the ward regularly received new HIV testing logs and logs for documenting the provision of family planning services, for example. Handbooks and workshop participant activity books seemed to reproduce in desk drawers as the nurses attended various trainings related to basic emergency obstetric and neonatal care (BEmONC), Helping Babies Breathe (HBB), the nonpneumatic antishock garment (NASG), HIV testing, cervical cancer screening, or TB prevention.

Paperwork generally, makes up the stuff of all forms of administration in Tanzania. The open registry and the Medical Records Department in the hospital played important roles in this documentary landscape too. The open registry 
housed all the official details of a person's employment at the hospital, including evaluations, assignments, reprimands, and mistakes. The Medical Records Department held the only evidence of care given and received-the only official record of a patient's presence and, sometimes, death within the walls of the hospital. On the maternity ward, the paperwork, as an outgrowth of (bio)bureaucratic expansion, became a player in the social and professional life of the ward.

\section{THE ORIGINS OF MATERIAL SCARCITY}

Actors at the Mawingu Regional Hospital worked to provide care to patients across wards and departments, all the while against a background of historically rooted scarcity and administrative neglect in this peripheral region of the country. Though colonial correspondence refers to the facility that existed on the site of Mawingu in the 1920 s as a hospital, the descriptions of the few squat, thatchedroof buildings and available services exemplify the racially stratified health disparities operating throughout the British Empire. In areas with more direct economic benefit to the colonial regime, or with a larger colonial settler population, health care services were much more robust. Because of the remoteness of Sumbawanga from centers of political administration, then as now, there were few options for medical services for both the colonial and local population.

An archaeology of what has always been the hospital's site might reveal unseen vestiges of the first facility's mud walls; of the kitchen table on which subassistant surgeon Dr. Ghanekar conducted operations in 1936 because of the shortage of other facilities and equipment; ${ }^{3}$ or of the layered complaints of generations of health care workers-European medical officers, Indian subassistant surgeons, and African assistant medical officers-posted to this remote town. Since that time, the hospital has struggled with retaining skilled staff members because of its isolated location and the lack of private practice and social opportunities for educated workers. ${ }^{9}$

Prior to state reforms in the 1990s, the people of Tanzania had access to free health care services, and for-profit, private sector activities in health care were limited..$^{10}$ In 1993 the government introduced user fees and then, shortly after, created exempted groups-pregnant women, children under five, elderly patients, HIV/AIDS patients, and severely impoverished patients seeking care-who, to the present day, do not have to pay for services. ${ }^{11}$ In 1996, the government undertook a process of health sector reform, which included decentralizing many aspects of health care planning and delivery to the district level. ${ }^{12}$ Decentralization allowed districts and facilities, such as the regional hospital, to determine their own supply needs but also required them to pay for them out of their budgets, the income for which came from the central government, as well as user fees, insurance reimbursements, and the rural Community Health Funds (CHFs) into which families could pay. Decentralization placed the locus of control in the regions and districts 
but also put the fiscal burden of the health care system on economically disadvantaged populations in distant areas of the country, such as Rukwa.

Policy makers instituted fee exemptions to encourage vulnerable populations to utilize health care services to lower mortality rates. However, at many levels, these exemptions were essentially an unfunded mandate, lacking specific budget lines or any sustainable financial plans for continuing to pay for the care these populations needed, especially in the context of decentralization. While the central government budget does now include a budget line for maternal health care, the funds for these services are often supposed to come from outside donor contributions.

Regardless of the funding mechanism, all government health facilities throughout the country order their supplies from the Medical Stores Department (MSD). An act of Parliament in 1993 established MSD as a public, nonprofit organization, and it began functioning in $1994 \cdot{ }^{13}$ During my time in Tanzania, MSD was facing an incredible unpaid balance for supplies already disbursed. For example, in October 2014, Muhimbili National Hospital in Dar es Salaam alone had an unpaid balance of close to US\$4 million. ${ }^{14}$ A newspaper reported the collective debt of all health care facilities in the country was around US\$50 million or TZS 108.6 billion as of June $2015 .{ }^{15}$ In 2010, the WHO estimated the Tanzanian government spent $\$ 223$ million on rehabilitative and curative services. ${ }^{16}$ Using this number solely for the purposes of putting the debt owed to MSD in perspective, the debt would (in 2010) represent 22.4 percent of the government's total health expenditure. It was this enormous amount of accumulating debt that caused MSD to issue a statement limiting (or, in some cases entirely stopping) distribution until the government reached a plan to settle the balance. Yet facilities like Mawingu relied on funds from the central government to pay their debts at MSD, as well as purchase new supplies. If the government was slow to disburse these monies, because of either lack of funds in the budget from low revenue generation or delayed contributions from donors, facilities could be left without the means to pay MSD and, as in 2014, without any supplies. In September 2014, a sign appeared on the maternity ward that read, "Announcement: For now, there are no oxytocin injections. Therefore, the few there are, are only for emergencies." Oxytocin is the first-line drug of choice for preventing postpartum hemorrhage, and every woman is supposed to receive it immediately after giving birth. A shortage of this basic supply was a result of these countrywide problems.

As 2014 wound on, a perfect storm began brewing, one that would further challenge Mawingu's abilities to operate and provide services. Poor-quality services at lower levels of the referral chain resulted in ever-increasing numbers of patients at Mawingu Regional Hospital, overburdening this facility as it took on patients that could have been served closer to their homes. Poor services or lack of competent providers in village dispensaries and fewer resources for complicated problems all drive patients to higher levels of care. The hospital has seen a dramatic increase in the number of patients served each year just since 2010, but this 
increase in clients has not been met by a concomitant increase in physical capacity. ${ }^{17}$ The result is a bed occupancy rate of 172 percent, such a significant degree of overcrowding that patients are often forced to share beds.

In addition to improved standards of care at the regional hospital, a lack of money in the community in late 2014 was driving more and more pregnant women to bypass lower-level facilities to give birth in the hospital. This decision was driven by rumors of good care, yes, but also by the belief that the hospital would have more supplies available, so that patients would not need to pay for supplies out of pocket as they would have had to in the village. Because of MSD's refusal to disburse supplies on credit any longer, health care facilities at lower levels became increasingly bare.

In Rukwa, people get much of their annual income from selling agricultural products, which they usually harvest after the last rains, sometimes as early as June and as late as September. They then use these funds for household expenses, including health care. In 2014, the government, one of the largest buyers of individual farmers' crops, acquired maize on loan with the promise of future payment. In November 2014, I read in a newspaper that members of Parliament were questioning the delay in payments for the more than three million tons of maize the government had already purchased on loan. In some villages, as late as April 2015, community members told me they were still waiting for the cash from the government for maize bought more than six months prior. In addition to delayed payments for purchased crops, the timing of the crisis at MSD coincided with particularly low market prices for maize in 2014. There was a bumper crop, with some farmers producing more than ever before, but the government had already amassed a surplus that could feed Tanzania for a projected three years. Therefore, the government was not buying maize from farmers at prices even remotely close to those of the harvest of 2013. For many months following the harvest, as I traveled around the Rukwa region, I could see maize in gunny sacks piled high under blue tarps, waiting for buyers who never came. This means many families had nothing to sell and had not yet received any money. Preserving what little cash they could access was vital for community members during this period because they were quickly running out of resources as the prospect of payments from the harvest months earlier became increasingly less certain. Bypassing local facilities to avoid buying supplies or medications was one strategy some families used to try to save some money.

Delayed or no payments for the maize harvest led to cash-poor families who could barely pay for the essentials, let alone unexpected costs at health care facilities. Without cash, community members also could not contribute to the community health insurance schemes known as CHFs. Without the money from these funds, most dispensaries and health care centers were unable to stock essential medications and supplies. ${ }^{18}$ The lack of equipment in these lower-level facilities shifted the burden of care from primary level dispensaries to the district health center and 
designated district hospitals but primarily to the regional hospital, which struggled to stay afloat throughout this time. Patients and their families lacked information about the health care system and the CHFs because of poor communication throughout all levels of the health care sector and local governments. They did not understand why supplies were not available. This poor communication and lack of transparency created an environment characterized by high levels of suspicion and mistrust between communities and the professionals meant to work with, and for, them in order to improve their health and well-being.

The health care situation in communities throughout the Rukwa region directly affected Mawingu, most obviously by increasing the number of patients seeking care at the hospital when services were lacking at the village dispensary level. The regional hospital absorbed more and more of these clients, who often used what cash they had to get to the hospital. Families arrived at Mawingu with high expectations for free care and supplies aplenty but too often encountered nurses' demands that they rush out to buy medication or gloves or intravenous fluids. While the hospital accepted these patients from the districts, the district health administration did not provide any funds from their budgets to help support the regional hospital, even as they off-loaded patients from their populations. Because care for pregnant women was, by policy, free, this increased patient load in the maternity ward was particularly worrying and an enormous drain on hospital resources.

The regional hospital operated for months at a time with almost no support from the government for the care the hospital provided for the exempt groups, most significantly pregnant women. The regional medical officer repeatedly railed in morning meetings, "We should not be conducting normal deliveries! We are a referral hospital. Why are they not doing their work at the dispensaries? I would turn them away at the gates, but you cannot risk a woman giving birth there after you have turned her away. But, really, this is not sustainable!" The increase in patient load without increased resources meant that nurses and doctors, struggling to prevent deaths on the maternity ward, had to work even harder to ensure that women and their babies did not fall through the ever-widening cracks of the hospital's system. The nurses and doctors continued to strive to do their best without first-line medications of choice, or any at all: they improvised catheters from nasogastric tubes and gloves, and they cut umbilical cords by hacking at them with the tiny sharp point of a needle from a syringe instead of using scissors or razor blades.

The nurses and doctors worked together with patients to address women's needs while they were pregnant and in labor, even as the central Tanzanian government did not disburse funds in a timely manner. Supplies from MSD were slow to arrive at the hospital, and their absence worked to undermine biomedicine's reputation in the community. Beyond just the technical aspects of care that Tanzanians expected to find at health facilities, the socialist period's expectations of state care for citizens continued to permeate the ethos of Tanzania, resulting in disappointment when care failed or was unavailable. And yet, many of the country's more recent 
policies had resulted in a health care system that was unable to keep pace with increased demand; hospitals like Mawingu were receiving more and more patients without the necessary support from the central government. One way in which this mismatch in supply and demand manifested was through the ongoing high maternal mortality ratio in the country and at the hospital. 